\title{
Variations in the Use of Racing Coil and Iridium Spark Plugs in Gasoline Engines, A Comparative Study
}

\section{Studi Perbandingan Variasi Penggunaan Koil Racing dan Busi Iridium pada Motor Bensin}

Oka Sandrio Putra ${ }^{1 *}$, M Nasir 2

\begin{abstract}
The increasing number of vehicles has resulted in an increase in air pollution. Innovations were made to improve engine performance and reduce levels of exhaust emissions. This research was conducted on several types of racing coil and iridium spark plugs which will be examined for their ability to reduce levels of exhaust emissions. Several types of racing coil and spark plug racing (iridium) are mounted on a gasoline motor and then tested and compared the exhaust emissions. The gasoline engine used is the Honda Supra X 125 motorcycle, the results of the study indicate the Blue Thunder coil and NGK Iridium are able to improve engine performance and reduce levels of exhaust emissions.
\end{abstract}

\section{Keywords}

racing coil, spark plug racing, exhaust emissions

\begin{abstract}
Abstrak
Meningkatnya jumlah kendaraan mengakibatkan peningkatan pencemaran udara. Inovasi dilakukan guna meningkatkan unjuk kerja engine dan mengurangi kadar emisi gas buang. Penelitian ini dilakukan terhadap beberapa jenis koil racing dan busi iridium yang akan diteliti kemampuanya dalam mengurangi kadar emisi gas buang. Beberapa jenis koil racing dan busi racing (iridium) dipasangkan pada sebuah motor bensin dan kemudian diuji dan dibandingkan emisi gas buangnya. Motor bensin yang digunakan adalah sepeda motor Honda Supra X 125, hasil penelitian menunjukkan koil Blue Thunder dan NGK Iridium mampu memperbaiki unjuk kerja mesin dan mengurangi kadar emisi gas buang.
\end{abstract}

Kata Kunci

koil racing, busi racing, emisi gas buang

${ }_{1}^{1}$ Program Studi Teknik Kendaraan Ringan, SMKN 1 Gunung Talang

Jl. Lintas Sumatera Aro Talang, Kec. Gunung Talang Kab. Solok Sumatera Barat, Indonesia

2 Jurusan Teknik Otomotif, Universitas Negeri Padang

JIn. Prof. Dr. Hamka Air Tawar Padang 25131 Indonesia

*okasandrioputra@yahoo.com

Submitted : December 24, 2018. Accepted : January 05, 2019. Published : January 15, 2019. 


\section{PENDAHULUAN}

Latar belakang dari penelitian ini adalah masalah penggunaan bahan bakar fosil yang tidak sesuai dengan karakter mesin yang menyebabkan terjadinya pembakaran tidak sempurna secara otomatis mengeluarkan emisi gas buang yang berbahaya bagi manusia dan lingkungan. Hasil dari proses pembakaran bahan bakar tersebut akan menghasilkan emisi gas buang yang dapat menyebabkan polusi udara.

Banyak inovasi yang dilakukan dalam meningkatkan unjuk kerja engine hingga didapatkan kemampuan maksimumnya.Salah satu perlakuan untuk meningkatkan unjuk kerja engine dan emisi gas buang adalah dengan memperbaiki kualitas pembakaran bahan bakar di dalam ruang bakar. Langkah untuk mengurangi pencemaran udara dari emisi gas buang yang di hasilkan oleh mesin pada putaran rendah sampai tinggi dapat di lakukan melalui pembuatan desain baru yang lebih baik ( untuk mesin baru yang akan diproduksi) atau dengan memberikan peralatan tambahan. oleh karena itu penulis meneliti peralatan tambahan yang digunakan dalam memperbaiki kerja mesin tersebut, peraltan tersebut antara lain yaitu koil racing dan busi racing tipe Iridium.

Tujuan dari penelitian ini adalah untuk mengetahui Mengetahui emisi gas buang CO dan HC ketika memakai beberapa jenis koil racing dan busi racing (iridium) pada sepeda motor Honda Supra X 125 dan Membandingkan emisi gas buang CO dan HC ketika memakai beberapa jenis koil racing dan busi racing (Iridium) pada sepeda motor Honda Supra X 125.

\section{Pembakaran}

Pembakaran merupakan proses oksidasi cepat bahan bakar disertai dengan produksi panas dan cahaya[1]. Syarat terjadinya pembakaran yang baik pada suatu motor yaitu adanya tekanan kompresi yang cukup, campuran bahan bakar dan udara cukup, dan Suhu yang cukup tinggi untuk pembakaran.Ada dua kemungkinan yang terjadi pada pembakaran motor bensin yaitu, pembakran sempurna (normal), dan pembakaran tidak sempurna[2].

\section{Emisi Gas Buang}

Emisi gas buang merupakan polutan yang mengotori udara yang dihasilkan dari gas buang kendaraan, adapun emisi tersebut adalah Hidrokarbon, KarbonMonoksida, Nitrogen Oksida[3].Emisi gas buang merupakan polutan yang bersumber dari gas buang kendaraan pribadi maupun umum yang dilepas ke udara dan memberikan efek bagi manusia maupun ekosistem lingkungan[4].kesimpulan dari pendapat diatas adalah emisi gas buang adalah segala sesuatu yang timbul karena adanya aktifitas manusia terutama pada pemakaian kendaraan bermotor dan sektor industri, yang dapat menyebabkan naiknya tingkat polusi udara. Emisi gas buang yang berlebihan dapat memberikan dampak negatif pada makhluk hidup maupun ekosistem lingkungan.

\section{Faktor yang Mempengaruhi Emisi Gas Buang}

Faktor yang mempegaruhi kandungan emisi gas buang yang dihasilkan dari proses pembakaran pada motor bensin, diantaranya yaitu: a. campuran bahan bakar dan udara, b. timing pengapian, c. decelartion engine, d. kecepatan mesin[5].

\section{Koil}

Koil dari sistem penyalaan adalah merupakan lilitan kawat khusus yang berguna sebagai alat untuk menaikkan tegangan listrik dari baterai menjadi tegangan yang cukup tinggi sehingga mampu meloncat pada celah busi dan menimbulkan bunga api yang akhirnya dapat membakar campuran bahan bakar dengan udara yang ada di dalam silinder dan akhirnya motor dapat menghasilkan tenaga[3]. Berdasarkan bentuk serta kegunaannya, koil dapat dibedakan menjadi 2 jenis yaitu:Desain Koil Standar. Koil pengapian ini digunakan untuk pengapian tegangan tinggi pada mesin sepeda motor.Desain Koil pengapian performance tinggi (Koil Racing). Koil ini sedikit berbeda dengan koil standar dimana koil ini sengaja diciptakan 
untuk menghasilkan tegangan yang tinggi guna menyempurnakan proses pembakaran yang terjadi pada ruang bakar[6].

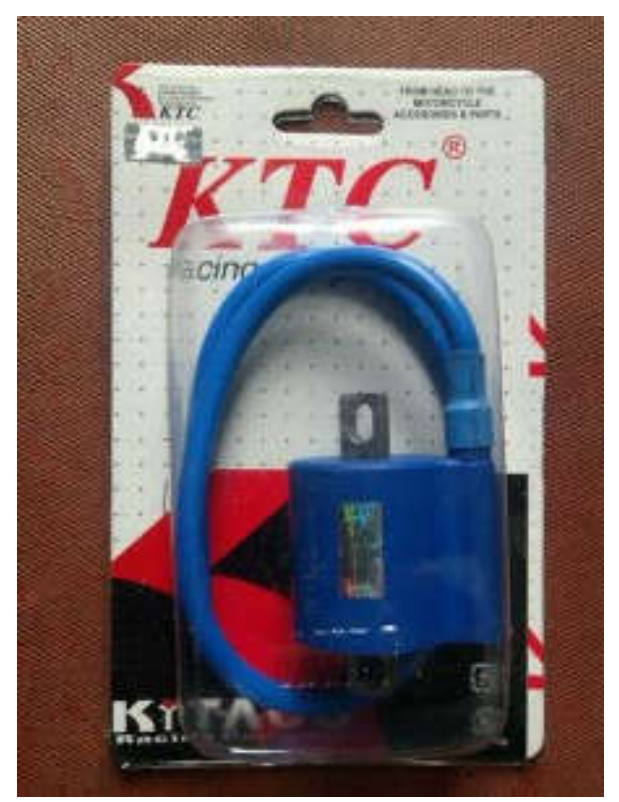

\section{Busi}

Gambar 1. Koil Tipe Racing

Busi merupakan salahsatu komponen utama dan penting dalam sistem pengapian, yaitu sebagai komponen yang langsung menghasilkan loncatan/percikan bunga api dari ujung elektroda busi ke masa busi yang seketika akan terjadi pembakaran campuran bahan bakar dan udara dalam ruang bakar kendaraan[7]. Busi iridium merupakan busi dengan inti elektroda berdiameter sangat kecil yaitu 0,4-0,6 mm terbuat dari iridium alloy yang kuat dan tahan panas, sehingga dengan bentuk yang kecil tegangan yang di butuhkan untuk pengapian menjadi rendah.

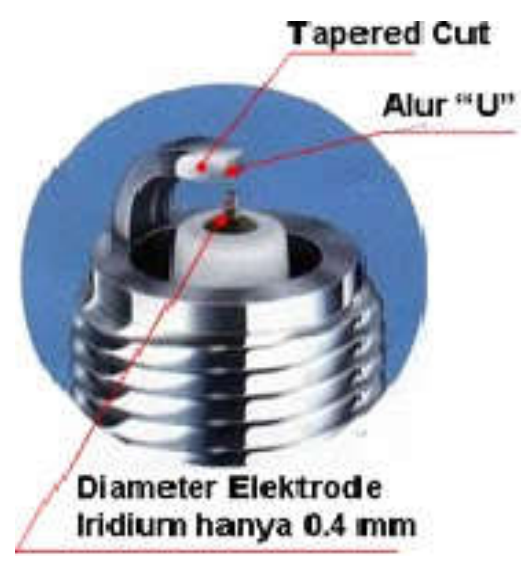

Gambar 2. Jenis Busi Iridium

\section{METODE PENELITIAN}

Penelitian ini dilakukan untuk mengetahui adanya perbedaan antara dua perlakuan berbeda pada satu objek yang sama, oleh sebab itu penelitian ini menggunakan metode eksperimental.Penelitian ini dimaksudkan untuk mencari perbandingan pemakaian koil tipe racing dan busi racing(jenis iridium) terhadap konsumsi bahan bakar dan emisi gas buang pada 
sepeda motor supra X 125cc melalui pengumpulan data secara langsung, baik melalui perlakuan maupun merujuk pada data yang sudah ada. Kelompok pertama tidak diberi perlakuan dan kelompok kedua diberi perlakuan (X) yang disebut kelompok eksperimen. Objek dari penelitian ini adalah sepeda motor supra x 125 cc,Sumber data pada penelitian ini diperoleh dari hasil pengujian Koil tipe Standar,Busi tipe Standar dan Koil tipe Racing, Busi tipe Racing(jenis Iridium) yang akan dilaksanakan di Workshop Teknik Otomotif Universitas Negeri Padang. Data pada penelitian ini diambil dengan cara menggunakan RPM 1000, 1500, 2000, 2500, 3000 dengan mengunakanbusi standar setelah didapatkan hasil tersebut kemudian busi diganti dengan busi iridium, kemudian digunakan juga koil racing kitaco dengan busi standar digabungkan, kemudian digunakan busi iridium merek NGK dan Denso, setelah itu digunakan koil racing Blue Thunder dengan 3 merek busi standar ngk iridium dan denso iridium .

\section{HASIL DAN PEMBAHASAN}

\section{Hasil}

Setelah dilakukan pengujian didapatkan hasil data sebagai berikut

\section{Data Hasil Pengujian Emisi Gas buang}

Tabel 1. Data Hasil Pengujian kandungan emisi gas buang menggunakan Koil standar dan Busi standar.

\begin{tabular}{|c|c|c|c|c|c|c|c|c|}
\hline \multirow{3}{*}{$\begin{array}{l}\text { Putaran } \\
\text { Mesin } \\
\text { (rpm }\end{array}$} & \multirow{3}{*}{$\begin{array}{l}\text { Suhu } \\
\text { Mesin } \\
\left({ }^{\circ} \mathrm{C}\right)\end{array}$} & \multirow[t]{3}{*}{$\begin{array}{l}\text { Waktu } \\
\text { (Menit) }\end{array}$} & \multicolumn{6}{|c|}{$\begin{array}{l}\text { Mesin Dengan Sistem Pengapian Koil Standar } \\
\text { dan Busi standar }\end{array}$} \\
\hline & & & \multicolumn{3}{|c|}{$\mathrm{CO}(\%)$} & \multicolumn{3}{|c|}{$\mathrm{HC}(p p m)$} \\
\hline & & & & Uj12 & $\begin{array}{c}\text { Rata-rata } \\
(\%)\end{array}$ & $\begin{array}{l}\text { Ujil } 1 \\
(\text { ppm) }\end{array}$ & $\begin{array}{l}\text { Uj1 } 2 \\
(p p m)\end{array}$ & $\begin{array}{c}\text { Rata-rata } \\
\text { (ppm) }\end{array}$ \\
\hline 1500 & $0-90$ & 1 & 2,02 & 2,13 & 2,075 & 538 & 755 & 646,5 \\
\hline 2000 & $80-90$ & 1 & 2,88 & 3,02 & 2,95 & 436 & 457 & 446,5 \\
\hline 2500 & $80-90$ & 1 & 4,37 & 4,06 & 4,215 & 448 & 608 & 528 \\
\hline 3000 & $80-90$ & 1 & 4,66 & 4,65 & 4,655 & 783 & 744 & 763,5 \\
\hline
\end{tabular}

Tabel 2. Data Hasil Pengujian kandungan emisi gas buang yang menggunakan Koil Standar dan Busi NGK Iridium.

\begin{tabular}{|c|c|c|c|c|c|c|c|c|}
\hline $\begin{array}{c}\text { Putaran } \\
\text { Mesin } \\
(\mathrm{rpm}\end{array}$ & $\begin{array}{c}\text { Suhu } \\
\text { Mesin } \\
\left({ }^{\circ} \mathrm{C}\right)\end{array}$ & \multirow{2}{*}{$\begin{array}{c}\text { Waktu } \\
\text { (Menit) }\end{array}$} & \multicolumn{6}{|c|}{ Mesin Dengan Sistem Pengapian Koil Standar daan } \\
\cline { 4 - 9 } & & & $\begin{array}{c}\text { Co (\%) } \\
(\%)\end{array}$ & $\begin{array}{c}\text { Uji } 2 \\
(\%)\end{array}$ & $\begin{array}{c}\text { Rata-rata } \\
(\%)\end{array}$ & $\begin{array}{c}\text { Uji } 1 \\
(p p m)\end{array}$ & $\begin{array}{c}\text { Uji } 2 \\
(p p m)\end{array}$ & $\begin{array}{c}\text { Rata-rata } \\
(p p m)\end{array}$ \\
\hline 1500 & $80-90$ & 1 & 1,54 & 1,91 & 1,725 & 333 & 949 & 641 \\
\hline 2000 & $80-90$ & 1 & 2,69 & 2,61 & 2,65 & 332 & 383 & 357,5 \\
\hline 2500 & $80-90$ & 1 & 3,99 & 3,54 & 3,765 & 475 & 470 & 427,5 \\
\hline 3000 & $80-90$ & 1 & 2,41 & 2,88 & 2,645 & 680 & 615 & 647,5 \\
\hline
\end{tabular}

Tabel 3. Data Hasil Pengujian kandungan emisi gas buang yang menggunakan Koil Standar dan

\begin{tabular}{|c|c|c|c|c|c|c|c|c|}
\hline \multirow{3}{*}{$\begin{array}{l}\text { Putaran } \\
\text { Mesin } \\
\text { (rpm }\end{array}$} & \multirow{3}{*}{$\begin{array}{l}\text { Suhu } \\
\text { Mesin } \\
\left({ }^{\circ} \mathrm{C}\right)\end{array}$} & \multirow[t]{3}{*}{$\begin{array}{l}\text { Waktu } \\
\text { (Menit) }\end{array}$} & \multicolumn{6}{|c|}{$\begin{array}{c}\text { Mesin Dengan Sistem Pengapian Koil Standar dan } \\
\text { Busi Denso Iridium }\end{array}$} \\
\hline & & & \multicolumn{3}{|c|}{$\mathrm{CO}(\%)$} & \multicolumn{3}{|c|}{$\mathrm{HC}(p p m)$} \\
\hline & & & $\begin{array}{l}\text { Uji } 1 \\
(\%)\end{array}$ & $\begin{array}{c}\text { Uji } 2 \\
(\%)\end{array}$ & $\begin{array}{l}\text { Rata- } \\
\text { rata } \\
\text { (\%) }\end{array}$ & $\begin{array}{c}\text { Uji } 1 \\
(p p m)\end{array}$ & $\begin{array}{l}\text { Uji } 2 \\
(p p m)\end{array}$ & $\begin{array}{c}\text { Rata-rata } \\
\text { (pprin) }\end{array}$ \\
\hline 1500 & $80-90$ & 1 & 1,21 & 1,23 & 1,22 & 454 & 680 & 567 \\
\hline 2000 & $80-90$ & 1 & 2,74 & 2,37 & 2,555 & 391 & \begin{tabular}{|l|}
497 \\
\end{tabular} & 444 \\
\hline 2500 & $80-90$ & 1 & 2,66 & 2,97 & 2,815 & 228 & 527 & 377,5 \\
\hline 3000 & $80-90$ & 1 & 4,54 & 4,50 & 4,52 & 506 & 752 & 629 \\
\hline
\end{tabular}


Tabel 4. Data Hasil Pengujian kandungan emisi gas buang yang menggunakan Koil racing Kitaco dan Busi Standar

\begin{tabular}{|c|c|c|c|c|c|c|c|c|}
\hline \multirow{4}{*}{$\begin{array}{l}\text { Putaran } \\
\text { Mesin } \\
\text { (rpm }\end{array}$} & \multirow{4}{*}{$\begin{array}{l}\text { Suhu } \\
\text { Mesin } \\
\left({ }^{\circ} \mathrm{C}\right)\end{array}$} & \multirow{4}{*}{$\begin{array}{l}\text { Waktu } \\
\text { (Menit) }\end{array}$} & \multicolumn{6}{|c|}{ Mesin Dengan Sistem Pengapian Koil Kitaco dian } \\
\hline & & & \multicolumn{6}{|c|}{ Busi Standar } \\
\hline & & & \multicolumn{3}{|c|}{$\mathrm{CO}(\%)$} & \multicolumn{3}{|c|}{$\mathrm{HC}(p p m)$} \\
\hline & & & \begin{tabular}{|c} 
Uji 1 \\
(\%)
\end{tabular} & $\begin{array}{c}\text { Uji } 2 \\
\text { (\%) }\end{array}$ & $\begin{array}{c}\text { Rata-rata } \\
(\%)\end{array}$ & \begin{tabular}{|c|c} 
Uji 1 \\
$($ (ppm)
\end{tabular} & $\begin{array}{c}\text { Uji } 2 \\
(p p m)\end{array}$ & $\begin{array}{c}\text { Ratarata } \\
\text { (perm) }\end{array}$ \\
\hline 1500 & $80-90$ & 1 & 1,57 & 1,90 & 1,735 & 437 & 660 & 548,5 \\
\hline 2000 & $80-90$ & 1 & 2,10 & 1,47 & 1,785 & 187 & 62 & 124,5 \\
\hline 2500 & $80-90$ & 1 & 3,27 & 3,08 & 3,175 & 90 & 660 & 37d \\
\hline 3000 & $80-90$ & 1 & 4,15 & 3,76 & 3,955 & 547 & 576 & 561,5 \\
\hline
\end{tabular}

Tabel 5. Data Hasil Pengujian kandungan emisi gas buang yang menggunakan Koil Racing Kitaco dan Busi Racing NGK Iridium.

\begin{tabular}{|c|c|c|c|c|c|c|c|c|}
\hline \multirow{3}{*}{$\begin{array}{l}\text { Putaran } \\
\text { Mesin } \\
\text { (rpm }\end{array}$} & \multirow{3}{*}{$\begin{array}{c}\text { Suhu } \\
\text { Mesin } \\
\left({ }^{\circ} \mathrm{C}\right)\end{array}$} & \multirow[t]{3}{*}{$\begin{array}{l}\text { Waktu } \\
\text { (Menit) }\end{array}$} & \multicolumn{6}{|c|}{$\begin{array}{c}\text { Mesin Dengan Sistem Pengapian Koil Kitaco dar } \\
\text { Busi NGK Iridium }\end{array}$} \\
\hline & & & \multicolumn{3}{|c|}{$\mathrm{CO}(\%)$} & \multicolumn{3}{|c|}{$\mathrm{HC}(p p m)$} \\
\hline & & & $\begin{array}{c}\text { Uji } 1 \\
(\%)\end{array}$ & $\begin{array}{l}\text { Uji } 2 \\
(\%)\end{array}$ & $\begin{array}{c}\text { Rata-rata } \\
\text { (\%) }\end{array}$ & $\begin{array}{l}\text { Uji } 1 \\
(p p m)\end{array}$ & $\begin{array}{c}\mathrm{Uji} 2 \\
(p p m)\end{array}$ & $\begin{array}{c}\text { Rata-rata } \\
(\mathrm{ppm})\end{array}$ \\
\hline 1500 & $80-90$ & 1 & 1,38 & 1,78 & 1,580 & 504 & 545 & 524,5 \\
\hline 2000 & $80-90$ & 1 & 0,89 & 0,46 & 0,675 & 59 & 17 & 38 \\
\hline 2500 & $80-90$ & 1 & 3,76 & 3,57 & 3,665 & 705 & 644 & 674,5 \\
\hline 3000 & $80-90$ & 1 & 4,18 & 0,58 & 2,380 & 662 & 554 & 608 \\
\hline
\end{tabular}

Tabel 6. Data Hasil Pengujian kandungan emisi gas buang yang menggunakan Koil Kitacor dan Busi Racing Denso Iridium.

\begin{tabular}{|c|c|c|c|c|c|c|c|c|}
\hline \multirow{3}{*}{$\begin{array}{l}\text { Putaran } \\
\text { Mesin } \\
\text { (rpm }\end{array}$} & \multirow{3}{*}{$\begin{array}{l}\text { Suhu } \\
\text { Mesin } \\
\left({ }^{\circ} \mathrm{C}\right)\end{array}$} & \multirow[t]{3}{*}{$\begin{array}{l}\text { Waktu } \\
\text { (Menit) }\end{array}$} & \multicolumn{6}{|c|}{$\begin{array}{c}\text { Mesin Dengan Sistem Pengapian Koil Kitaco dian } \\
\text { Busi Denso Iridium }\end{array}$} \\
\hline & & & \multicolumn{3}{|c|}{$\mathrm{CO}(\%)$} & \multicolumn{3}{|c|}{$\mathrm{HC}(p p m)$} \\
\hline & & & $\begin{array}{l}\text { Uji } 1 \\
\text { (\%) }\end{array}$ & $\begin{array}{c}\text { Uji } 2 \\
\text { (\%) }\end{array}$ & $\begin{array}{l}\text { Rata-rata } \\
\text { (\%) }\end{array}$ & $\begin{array}{c}\text { Uji } 1 \\
\text { (ppm) }\end{array}$ & \begin{tabular}{|l|} 
Uji 2 \\
$($ (ppm)
\end{tabular} & $\begin{array}{c}\text { Rata-yat } \\
(p p m)\end{array}$ \\
\hline 1500 & $80-90$ & 1 & 0,21 & 0,81 & 0,510 & 352 & 664 & 508 \\
\hline 2000 & $80-90$ & 1 & 0,35 & 0,45 & 0,400 & 154 & 186 & 170 \\
\hline 2500 & $80-90$ & 1 & 3,65 & 3,94 & 3,795 & 758 & 566 & 662 \\
\hline 3000 & $80-90$ & 1 & 3,33 & 4,10 & 3,715 & 446 & 930 & 688 \\
\hline
\end{tabular}

Tabel 7. Data Hasil Pengujian kandungan emisi gas buang yang menggunakan Koil Racing Bluthander dan Busi Standar

\begin{tabular}{|c|c|c|c|c|c|c|c|c|}
\hline \multirow{3}{*}{$\begin{array}{c}\text { Putaran } \\
\text { Mesin } \\
\text { (rpm }\end{array}$} & \multirow{3}{*}{$\begin{array}{l}\text { Suhu } \\
\text { Mesin } \\
\left({ }^{\circ} \mathrm{C}\right)\end{array}$} & \multirow[t]{3}{*}{$\begin{array}{l}\text { Waktu } \\
\text { (Menit) }\end{array}$} & \multicolumn{6}{|c|}{$\begin{array}{c}\text { Mesin Dengan Sistem Pengapian Koil } \\
\text { Bluthanderdan Busi standar }\end{array}$} \\
\hline & & & \multicolumn{3}{|c|}{$\mathrm{CO}(\%)$} & \multicolumn{3}{|c|}{$\mathrm{HC}(p p m)$} \\
\hline & & & $\begin{array}{l}\text { Uji } 1 \\
(\%)\end{array}$ & $\begin{array}{c}\text { Uji } 2 \\
(\%)\end{array}$ & $\begin{array}{l}\text { Rata-rata } \\
\text { (\%) }\end{array}$ & $\begin{array}{c}\mathrm{Uji} 1 \\
(\text { (pom) }\end{array}$ & $\begin{array}{c}\mathrm{Uji} 2 \\
(p \rho m)\end{array}$ & $\begin{array}{l}\text { Rata a } \\
\text { (pogn }\end{array}$ \\
\hline 1500 & $80-90$ & 1 & 0,35 & 1,50 & 0,925 & 60 & 134 & 97 \\
\hline 2000 & $80-90$ & 1 & 3,02 & 2,67 & 2,845 & 438 & \begin{tabular}{|l|}
167 \\
\end{tabular} & 302,5 \\
\hline 2500 & $80-90$ & 1 & 3,89 & 3,75 & 3,820 & 555 & 460 & 507,5 \\
\hline 3000 & $80-90$ & 1 & 4,17 & 4,32 & 4,245 & 797 & 760 & 778,5 \\
\hline
\end{tabular}

Tabel 8. Data Hasil Pengujian kandungan emisi gas buang yang menggunakan Koil Bluthander dan Busi Racing NGK Iridium.

\begin{tabular}{|c|c|c|c|c|c|c|c|c|}
\hline \multirow{3}{*}{$\begin{array}{l}\text { Putaran } \\
\text { Mesin } \\
\text { (rpm }\end{array}$} & \multirow{3}{*}{$\begin{array}{l}\text { Suhu } \\
\text { Mesin } \\
\left({ }^{\circ} \mathrm{C}\right)\end{array}$} & \multirow[t]{3}{*}{$\begin{array}{l}\text { Waktu } \\
\text { (Menit) }\end{array}$} & \multicolumn{6}{|c|}{$\begin{array}{c}\text { Mesin Dengan Sistem Pengapian Koil Bluthander } \\
\text { dan Busi NGK Iridium }\end{array}$} \\
\hline & & & \multicolumn{3}{|c|}{$\mathrm{CO}(\%)$} & \multicolumn{3}{|c|}{$\mathrm{HC}(p p m)$} \\
\hline & & & $\begin{array}{l}\text { Uji } 1 \\
(\%)\end{array}$ & $\begin{array}{l}\text { Uji } 2 \\
(\%)\end{array}$ & $\begin{array}{c}\text { Rata-rata } \\
(\%)\end{array}$ & $\begin{array}{l}\text { Uji } 1 \\
(p p m)\end{array}$ & $\begin{array}{l}\text { Uji } 2 \\
(p p m)\end{array}$ & $\begin{array}{c}\text { Ratarata } \\
(p p \mathrm{~m})\end{array}$ \\
\hline 1500 & $80-90$ & 1 & 1,70 & 1,96 & 1,830 & 515 & 1197 & 856 \\
\hline 2000 & $80-90$ & 1 & 1,83 & 1,48 & 1,655 & 340 & 228 & 284 \\
\hline 2500 & $80-90$ & 1 & 0,80 & 0,63 & 0,715 & 611 & 333 & 472 \\
\hline 3000 & $80-90$ & 1 & 0,95 & \begin{tabular}{|l|l|}
0,67 \\
\end{tabular} & 0,810 & 439 & 348 & 393,5 \\
\hline
\end{tabular}


Tabel 9. Data Hasil Pengujian kandungan emisi gas buang yang menggunakan Koil Racing Bluthander dan Busi Denso Iridium

\begin{tabular}{|c|c|c|c|c|c|c|c|c|}
\hline \multirow{3}{*}{$\begin{array}{l}\text { Putaran } \\
\text { Mesin } \\
\text { (rpm }\end{array}$} & \multirow{3}{*}{$\begin{array}{l}\text { Suhu } \\
\text { Mesin } \\
\left({ }^{\circ} \mathrm{C}\right)\end{array}$} & \multirow{3}{*}{$\begin{array}{l}\text { Waktu } \\
\text { (Menit) }\end{array}$} & \multicolumn{6}{|c|}{$\begin{array}{l}\text { Mesin Dengan Sistem Pengapian Koil Blutharder } \\
\text { dan Busi Denso Iridium }\end{array}$} \\
\hline & & & \multicolumn{3}{|c|}{$\mathrm{CO}(\%)$} & \multicolumn{3}{|c|}{$\mathrm{HC}(p p m)$} \\
\hline & & & $\begin{array}{c}\text { Uji } 1 \\
(\%)\end{array}$ & \begin{tabular}{|l} 
Uji 2 \\
$(\%)$
\end{tabular} & \begin{tabular}{|c} 
Rata-rata \\
$(\%)$
\end{tabular} & $\begin{array}{l}\text { Uji } 1 \\
(p p m)\end{array}$ & \begin{tabular}{|l|} 
Uji 2 \\
$(p p m)$
\end{tabular} & $\begin{array}{c}\text { Ratế-rata } \\
(\rho, m)\end{array}$ \\
\hline 1500 & $80-90$ & 1 & 1,40 & 1,84 & 1,620 & \begin{tabular}{|l|}
331 \\
\end{tabular} & 299 & 315 \\
\hline 2000 & $80-90$ & 1 & 1,08 & 2,75 & 1,915 & 433 & 241 & $33 \frac{i}{4}$ \\
\hline 2500 & $80-90$ & 1 & 3,99 & 4,03 & 4,010 & 572 & 487 & 529,5 \\
\hline 3000 & $80-90$ & 1 & 4,33 & 4,54 & 4,435 & 888 & 612 & 750 \\
\hline
\end{tabular}

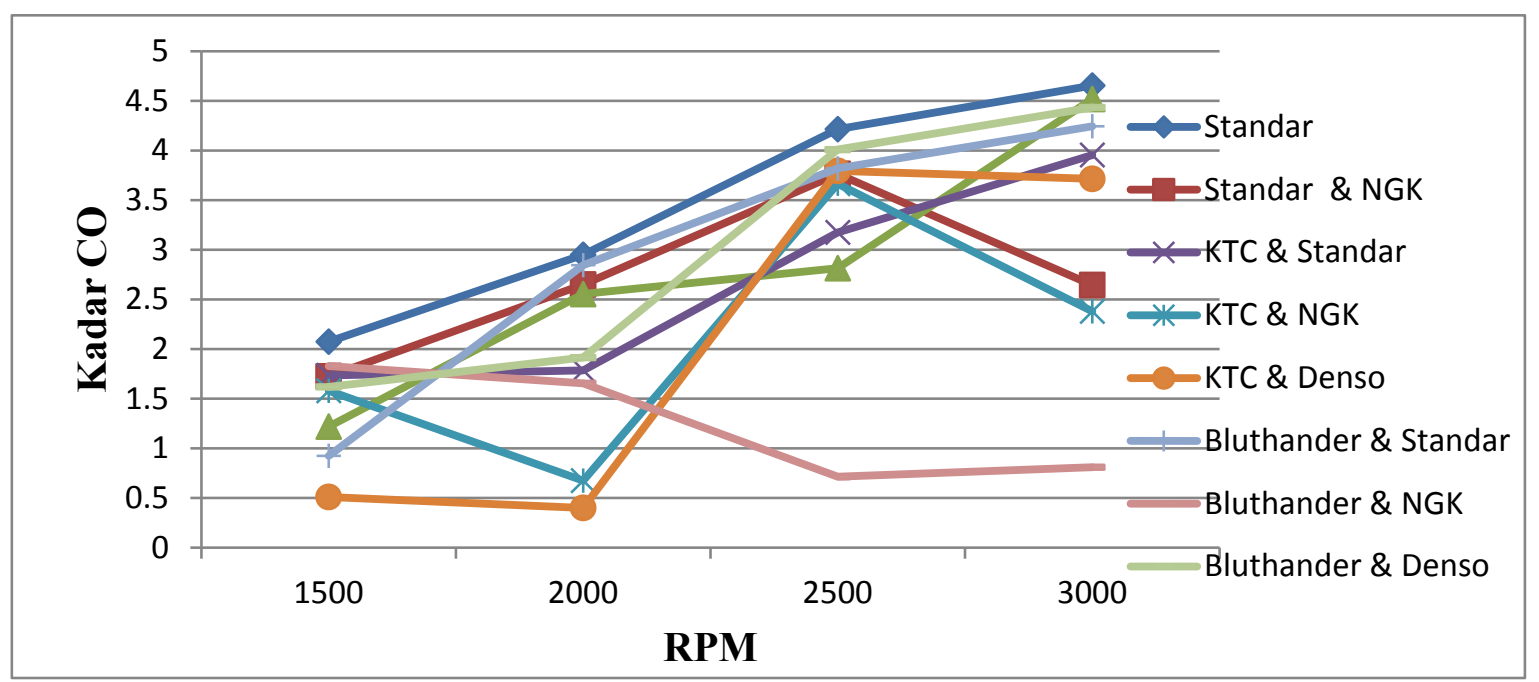

Gambar 3. Grafik Perbandingan kadar emisi CO yang dihasilkan dari Koil Racing dan Busi Iridium dengan Koil Standar dan Busi Standar

Berdasarkan grafik di gambar 3 dapat dilihat kadar CO dari kesembilan tipe perpeduan Koil Racing dan busi Iridium dengan Koil Standar dan Busi Standar selama 1 menit adalah berbeda - beda pada setiap putarannya. Putaran 1500,2000 Kadar CO paling rendah terdapat pada perpaduan koil Racing Kitaco dan Busi Denso Iridiumdan yaitu 0,51 dan 0,4 pada putaran 2500, 3000 kadar CO paling rendah perpaduan koil Racing Bluthander dan Busi NGK Iridium yaitu 0,715, dan 0,81 sedangkan kadar CO paling tinggi terdapat pada perpaduan koil standar dan busi standar yaitu putaran 1500 kadar CO nya 2,0675 pada putaran mesin 2000 kadar CO nya 2,95, untuk putaran 2500 kadar CO nya 4,215, sedangkan pada putaran 3000 kadar CO nya 4,655 .

Berdasarkan grafik dipada Gambar 4 dapat dilihat kadar HC dari kesembilan tipe perpeduan Koil Racing dan busi Iridium dengan Koil Standar dan Busi Standar selama 1 menit adalah berbeda - beda pada setiap putarannya. Pada putaran 1500 kadar HC paling rendah terdapat pada perpaduan koil racing bluthander dan busi standar yaitu 97ppm dan pada putaran 2000 kadar HC paling rendah terdapat pada perpaduan koil racing kitaco dan busi NGK iridium yaitu 38 ppm dan pada putaran 2500 kadar HC paling rendah terdapat pada perpaduan koil racing kitaco dan busi standaryaitu 375 ppm, pada putaran 3000 kadar HC paling rendah terdapat pada perpaduan koil racing bluthander dan busi ngk yaitu 393,5 ppm, sedangkan putaran 1500 paling tinggi terdapat pada perpaduan koil racing bluthander dan busi ngk iridium 856 ppm putaran 2000 yaitu perpaduan koil standar dan busi standar yaitu 446,5ppm putaran 2500 yaitu perpaduan koil racing kitaco dan busi ngk iridium yaitu 674,5 ppm putaran 3000 yaitu perpaduan koil racing bluthander dan busi standar yaitu 778,5ppm. 


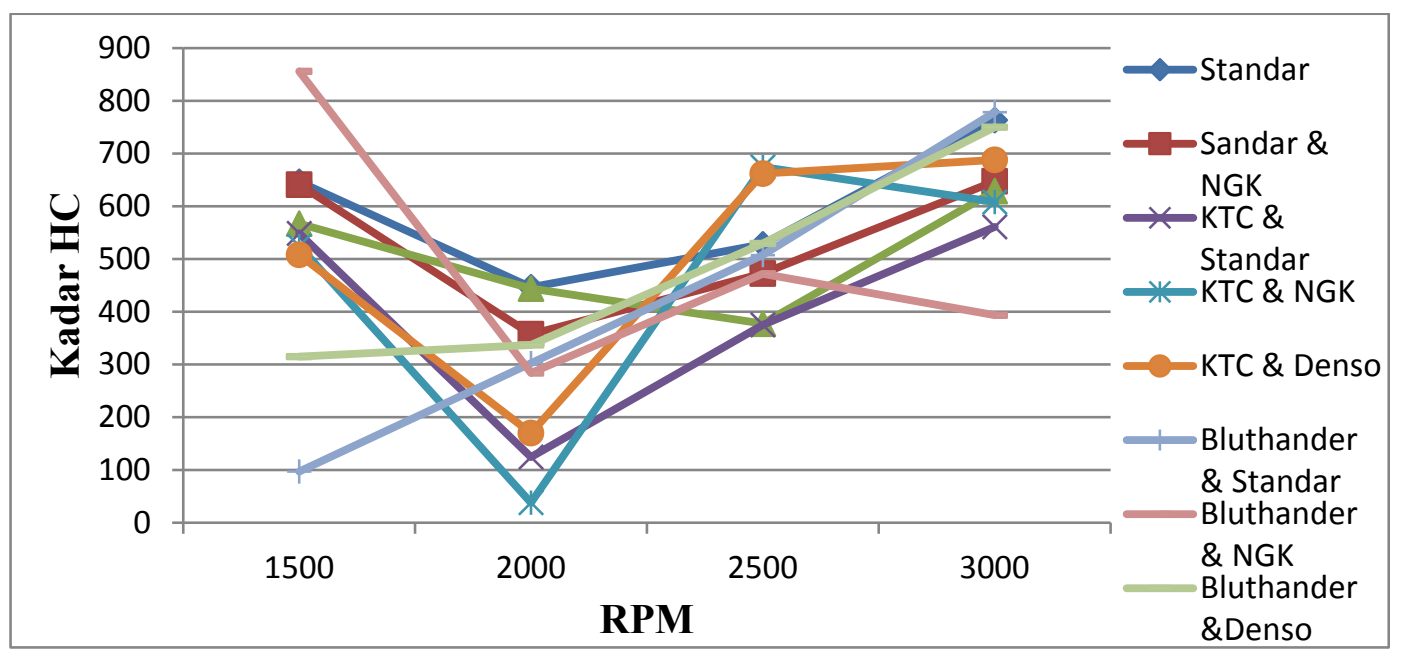

Gambar 4. Grafik Perbandingan kadar emisi HC yang dihasilkan dari Koil Racing dan Busi Iridium dengan Koil Standar dan Busi Standar

Emisi Karbon Monoksida (CO)

Koil Standar dan Busi NGK Iridium

Tabel 10.Hasil Uji T CO Koil Standar dan Busi NGK Iridium

\begin{tabular}{|c|c|c|c|c|c|c|c|c|c|c|}
\hline RPM & $x-y$ & Sx & Sy & $3 x^{2}$ & $s y^{2}$ & $3 x^{2}+3 y^{2}$ & $3 x^{2}+3 y^{2} / 2$ & $\sqrt{s x^{2}+s y^{2}}$ & $t$ & Șignifilkan \\
\hline 1500 & 0,35 & 0,077782 & 0,26163 & 0,00605 & 0,06845 & 0,0745 & 0,03725 & 0,193003 & 1,813447 & TidakSignifikan \\
\hline 2000 & 0,3 & 0,098995 & 0,056569 & 0,0098 & 0,0032 & 0,013 & 0,0065 & 0,080623 & 3,721042 & Şignifikan \\
\hline 2500 & 0,45 & 0,219203 & 0,318198 & 0,04805 & 0,10125 & 0,149 & 0,07465 & 0,273222 & 1,647015 & dak: Signifikan \\
\hline 3000 & 2,01 & 0,00071 & 0,33234 & 0,00005 & 0,11045 & 0,1105 & 0,05525 & 0,235053 & 8,551256 & Şignifikan \\
\hline
\end{tabular}

\section{Koil Standar dan Busi Denso Iridium}

Tabel 11.Hasil Uji T CO Koil Standr dan Busi Denso Iridium

\begin{tabular}{|c|c|c|c|c|c|c|c|c|c|c|}
\hline RPM & $x-y$ & $S x$ & Sy & $3 x^{2}$ & $5 y^{2}$ & $3 x^{2}+3 y^{2}$ & $3 x^{2}+3 y^{2} / 2$ & $\sqrt{s x^{2}+s y^{2}}$ & t & Șignifikan \\
\hline 1500 & 0,855 & 0,077782 & 0,014142 & 0,006050 & 0,0002 & 0,00625 & 0,003125 & 0,055902 & 15,294705 & Șignifikan \\
\hline 2000 & 0,395 & 0,098995 & 0,26163 & 0,0098 & 0,068450 & 0,07825 & 0,039125 & 0,1978 & 1,996963 & Tịidal-Signifikn \\
\hline 2500 & 1,4 & 0,219203 & 0,219203 & 0,048050 & 0,04805 & 0,0961 & 0,04805 & 0,219203 & 6,386771 & Signifikan \\
\hline 3000 & 0,135 & 0,007071 & 0,028284 & 0,00005 & 0,0008 & 0,00085 & 0,000425 & 0,020616 & 6,548462 & Şignifikan \\
\hline
\end{tabular}




\section{Koil Racing Kitaco dan Busi Standar}

Tabel 12.Hasil Uji TCO Koil Racing Kitco dan Busi Standar

\begin{tabular}{|c|c|c|c|c|c|c|c|c|c|c|}
\hline RPM & $x-y$ & $\mathrm{Sx}$ & Sy & $3 x^{2}$ & $3 y^{2}$ & $3 x^{2}+3 y^{2}$ & $3 x^{2}+3 y^{2} / 2$ & $\sqrt{s x^{2}+s y^{2}}$ & t & Signifikan \\
\hline 1500 & 0,34 & 0,077782 & 0,233345 & 0,00605 & 0,05445 & 0,0605 & 0,03025 & 0,173925 & 1,954863 & TidakSignifikan \\
\hline 2000 & 1,165 & 0,098995 & 0,445477 & 0,0098 & 0,19845 & 0,20825 & 0,104125 & 0,322684 & 3,610343 & Signifikan \\
\hline 2500 & 1,04 & 0,219203 & 0,13435 & 0,04805 & 0,01805 & 0,0661 & 0,03305 & 0,181797 & 5,720679 & Signifikan \\
\hline 3000 & 0,7 & 0,007071 & 0,275772 & 0,00005 & 0,07605 & 0,0761 & 0,03805 & 0,195064 & 3,588564 & Signifikan \\
\hline
\end{tabular}

\section{Koil Racing Kitaco dan Busi NGK Iridium}

Tabel 13.Hasil Uji T CO Koil Racing Kitaco dan Busi NGK Iridium

\begin{tabular}{|c|c|c|c|c|c|c|c|c|c|c|}
\hline RPM & $\frac{1}{s}-y$ & $\mathrm{Sx}$ & Sy & $3 x^{2}$ & $3 y^{2}$ & $3 x^{2}+3 y^{2}$ & $3 x^{2}+3 y^{2} / 2$ & $\sqrt{s x^{2}+s y^{2}}$ & $t$ & Signifilkan \\
\hline 1500 & 6,495 & 0,077782 & 0,282843 & 0,00605 & 0,08 & 0,16 & 0,08 & 0,282843 & 1,750089 & TitidakSSignifikn \\
\hline 2000 & 275 & 0,098995 & 0,304056 & 0,0098 & 0,09245 & 0,1849 & 0,09245 & 0,304056 & 7,482176 & Signifikan \\
\hline 2500 & , 55 & 0,219203 & 0,13435 & 0,04805 & 0,01805 & 0,0361 & 0,01805 & 0,13435 & 4,093776 & Signifikan \\
\hline 3000 & : 275 & 0,007071 & 2,545584 & 0,00005 & 6,48 & 12,96 & 6,48 & 2,545584 & 0,893704 & Tital-Signifikn \\
\hline
\end{tabular}

\section{Koil Kitaco dan Busi Denso Iridium}

Tabel 14.Hasil Uji T CO Koil Kitaco dan Busi Denso Iridium

\begin{tabular}{|c|c|c|c|c|c|c|c|c|c|c|}
\hline RPM & $\stackrel{x-y}{a}$ & $\mathrm{Sx}$ & Sy & $3 x^{2}$ & $5 y^{2}$ & $3 x^{2}+3 y^{2}$ & $3 x^{2}+3 y^{2} / 2$ & $\sqrt{s x^{2}+s y^{2}}$ & $t$ & Sißnifikan \\
\hline 1500 & 1,565 & 0,077782 & 0,424264 & 0,00605 & 0,18 & 0,36 & 0,18 & 0,424264 & 3,68874 & Siğnifikan \\
\hline 2000 & 2,55 & 0,098995 & 0,070711 & 0,0098 & 0,005 & 0,01 & 0,005 & 0,070711 & 36,062446 & Sißnifikan \\
\hline 2500 & 42 & 0,219203 & 0,205061 & 0,04805 & 0,04205 & 0,0841 & 0,04205 & 0,205061 & 2,048171 & TiêkakSignifikan \\
\hline 3000 & 94 & 0,007071 & 0,544472 & 0,00005 & 0,29645 & 0,5929 & 0,29645 & 0,544472 & 1,726443 & Tięak:Signifikn \\
\hline
\end{tabular}

\section{Koil Racing Bluthander dan Busi Standar}

Tabel 15.Hasil Uji T CO Koil Racing Bluthander dan Busi Standar

\begin{tabular}{|c|c|c|c|c|c|c|c|c|c|c|}
\hline RPM & $x-$ & $\mathrm{Sx}$ & Sy & $3 x^{2}$ & $3 y^{2}$ & $3 x^{2}+3 y^{2}$ & $3 x^{2}+3 y^{2} / 2$ & $\sqrt{s x^{2}+s y^{2}}$ & $t$ & Sighifikan \\
\hline 1500 & 1,15 & 0,077782 & 0,813173 & 0,00605 & 0,66125 & 1,3225 & 0,66125 & 0,813173 & 1,414214 & Tidak:Signifikan \\
\hline 2000 & 0,105 & 0,098995 & 0,247487 & 0,0098 & 0,06125 & 0,1225 & 0,06125 & 0,247487 & 0,424264 & TidalkSignifikan \\
\hline 2500 & 0,395 & 0,219203 & 0,098995 & 0,04805 & 0,0098 & 0,0196 & 0,0098 & 0,098995 & 3,990103 & Sighifikan \\
\hline 3000 & 0,41 & 0,007071 & 0,106066 & 0,00005 & 0,01125 & 0,0225 & 0,01125 & 0,106066 & 3,865517 & Sighifikan \\
\hline
\end{tabular}




\section{Koil Bluthander dan Busi NGK Iridium}

Tabel 16.Hasil Uji T CO Koil Bluthander dan Busi NGK Iridium

\begin{tabular}{|c|c|c|c|c|c|c|c|c|c|c|}
\hline RPM & $x-\frac{\partial}{d y}$ & Sx & Sy & $3 x^{2}$ & $5 y^{2}$ & $3 x^{2}+3 y^{2}$ & $3 x^{2}+3 y^{2} / 2$ & $\sqrt{s x^{2}+s y^{2}}$ & t & Sigaifilian \\
\hline 1500 & 0,245 & 0,077782 & 0,183848 & 0,00605 & 0,0338 & 0,0676 & 0,0338 & 0,183848 & 1,332624 & Tidak-Signifikn \\
\hline 2000 & 1,295 & 0,098995 & 0,247487 & 0,0098 & 0,06125 & 0,1225 & 0,06125 & 0,247487 & 5,23259 & Sighifikan \\
\hline 2500 & 3,5 & 0,219203 & 0,120208 & 0,04805 & 0,01445 & 0,0289 & 0,01445 & 0,120208 & 29,116162 & Sigififikan \\
\hline 3000 & 3,845 & 0,007071 & 0,19799 & 0,00005 & 0,0392 & 0,0784 & 0,0392 & 0,19799 & 19,420183 & Sighifikan \\
\hline
\end{tabular}

\section{Koil Racing Bluthander dan Busi Denso Iridium}

Tabel 17.Hasil Uji T CO Koil racing Bluthander dan Busi Denso Iridium

\begin{tabular}{|c|c|c|c|c|c|c|c|c|c|c|}
\hline RPM & $x-y$ & Sx & Sy & $3 x^{2}$ & $\mathrm{sy}^{2}$ & $3 x^{2}+3 y^{2}$ & $3 x^{2}+3 y^{2} / 2$ & $\sqrt{s x^{2}+s y^{2}}$ & $t$ & șignifilkan \\
\hline 1500 & 0,455 & 0,077782 & 0,311127 & 0,00605 & 0,0968 & 0,1936 & 0,0968 & 0,311127 & 1,462425 & idal-Signifikan \\
\hline 2000 & 1,035 & 0,098995 & 1,180868 & 0,0098 & 1,39445 & 2,7889 & 1,39445 & 1,180868 & 0,876474 & TidakSignifikan \\
\hline 2500 & 0,205 & 0,219203 & 0,028284 & 0,04805 & 0,0008 & 0,0016 & 0,0008 & 0,028284 & 7,247845 & Șignifikan \\
\hline 3000 & 0,22 & 0,007071 & 0,148492 & 0,00005 & 0,02205 & 0,0441 & 0,02205 & 0,148492 & 1,481557 & Tidak-Signifikn \\
\hline
\end{tabular}

Emisi Hidrokarbon (HC)

\section{Koil Standar dan Busi NGK Iridium}

Tabel 18.Hasil Uji T HC Koil Standar dan Busi NGK Iridium

\begin{tabular}{|c|c|c|c|c|c|c|c|c|c|c|}
\hline RPM & $x-\frac{1}{1}$ & Sx & Sy & $3 x^{2}$ & $3 y^{2}$ & $3 x^{2}+3 y^{2}$ & $3 x^{2}+3 y^{2} / 2$ & $\sqrt{s x^{2}+s y^{2}}$ & $t$ & Si snifikan \\
\hline 1500 & 5,4 & 153,442172 & 435,5777772 & 23544,5 & 189728 & 213272,5 & 106636,25 & 326,552063 & 0,016843 & TitịakSignifikan \\
\hline 2000 & 89 & 14,849242 & 36,06244584 & 220,5 & 1300,5 & 1521 & 760,5 & 27,577164 & 3,227308 & Signifikan \\
\hline 2500 & 555 & 113,137085 & 3,535533906 & 12800 & 12,5 & 12812,5 & 6406,25 & 80,039053 & 0,693412 & TighakSignifikan \\
\hline 3000 & $11 \%$ & 27,577164 & 45,96194078 & 760,5 & 2112,5 & 2873 & 1436,5 & 37,901187 & 3,060590 & signifikan \\
\hline
\end{tabular}

\section{Koil standar dan Busi Denso Iridium}

Tabel 19.Hasil Uji T HC Koil Standar dan Busi Denso Iridium

\begin{tabular}{|c|c|c|c|c|c|c|c|c|c|c|}
\hline RPM & $x-y$ & $S x$ & Sy & $3 x^{2}$ & $s y^{2}$ & $3 x^{2}+3 y^{2}$ & $3 x^{2}+s y^{2} / 2$ & $\sqrt{s x^{2}+s y^{2}}$ & $t$ & Șggnifikan \\
\hline 1500 & 79,5 & 153,442172 & 159,8061325 & 23544,5 & 25538 & 49082,5 & 24541,25 & 156,656471 & 0,507480 & $\mathrm{~T}$ dakSignifikan \\
\hline 2000 & 2,5 & 14,849242 & 74,95331881 & 220,5 & 5618 & 5838,5 & 2919,25 & 54,030084 & 0,046271 & TịdakSignifikan \\
\hline 2500 & $15(6,5$ & 113,137085 & 211,4249276 & 12800 & 44700,5 & 57500,5 & 28750,25 & 169,558987 & 0,887597 & TídakSignifikan \\
\hline 3000 & 134,5 & 27,577164 & 173,9482682 & 760,5 & 30258 & 31018,5 & 15509,25 & 124,536139 & 1,080008 & T:̣̂dakSignifikan \\
\hline
\end{tabular}




\section{Koil Racing Kitaco dan Busi Standar}

Tabel 20.Hasil Uji T HC Koil Racing Kitaco dan Busi Standar

\begin{tabular}{|c|c|c|c|c|c|c|c|c|c|c|}
\hline RPM & $x-y$ & $S x$ & Sy & $3 x^{2}$ & $3 y^{2}$ & $3 x^{2}+3 y^{2}$ & $3 x^{2}+3 y^{2} / 2$ & $\sqrt{s x^{2}+s y^{2}}$ & t & Sggnifikan \\
\hline 1500 & 98 & 153,442172 & 157,684812 & 23544,5 & 24864,5 & 48409 & 24204,5 & 155,577955 & 0,629909 & TidakSignifikan \\
\hline 2000 & 322 & 14,849242 & 88,388348 & 220,5 & 7812,5 & 8033 & 4016,5 & 63,375863 & 5,080799 & Sgmifilkan \\
\hline 2500 & 153 & 113,137085 & 403,050865 & 12800 & 162450 & 175250 & 87625 & 296,015202 & 0,516865 & Tiddalsignifikan \\
\hline 3000 & 202 & 27,577164 & 20,506097 & 760,5 & 420,5 & 1181 & 590,5 & 24,300206 & 8,312687 & Sigmifilkan \\
\hline
\end{tabular}

\section{Koil racing Kitaco dan Busi NGK Iridium}

Tabel 21. Hasil Uji T HC Koil Racing Kitaco dan Busi NGK Iridium

\begin{tabular}{|c|c|c|c|c|c|c|c|c|c|c|}
\hline RPM & $x-y$ & Sx & Sy & $3 x^{2}$ & $\mathrm{sy}^{2}$ & $3 x^{2}+3 y^{2}$ & $3 x^{2}+3 y^{2} / 2$ & $\sqrt{s x^{2}+s y^{2}}$ & t & s ganifikan \\
\hline 1500 & 122 & 153,442172 & 28,991378 & 23544,5 & 840,5 & 1681 & 840,5 & 28,991378 & 4,208148 & S gnifikan \\
\hline 2000 & 408 & 14,849242 & 29,698485 & 220,5 & 882 & 1764 & 882 & 29,698485 & 13,754910 & Stgnifikan \\
\hline 2500 & $-156,3$ & 113,137085 & 43,133514 & 12800 & 1860,5 & 3721 & 1860,5 & 43,133514 & $-3,396431$ & TidalkSignifikan \\
\hline 3000 & $155, \dot{\dot{s}}$ & 27,577164 & 76,367532 & 760,5 & 5832 & 11664 & 5832 & 76,367532 & 2,036206 & Tidalsignifikan \\
\hline
\end{tabular}

\section{Koil Racing Kitaco dan Busi Denso Iridium}

Tabel 22.Hasil Uji T HC Koil Racing Kitaco dan Busi Denso Iridium

\begin{tabular}{|c|c|c|c|c|c|c|c|c|c|c|}
\hline RPM & $x-y$ & Sx & Sy & $3 x^{2}$ & $\mathrm{sy}^{2}$ & $3 x^{2}+3 y^{2}$ & $3 x^{2}+3 y^{2} / 2$ & $\sqrt{s x^{2}+s y^{2}}$ & $t$ & Siguifilikan \\
\hline 1500 & 138,5 & 153,442172 & 220,617316 & 23544,5 & 48672 & 97344 & 48672 & 220,617316 & 0,627784 & Tidè่kSignifikan \\
\hline 2000 & 276,5 & 14,849242 & 22,627417 & 220,5 & 512 & 1024 & 512 & 22,627417 & 12,219689 & Sigkifikan \\
\hline 2500 & -134 & 113,137085 & 135,764502 & 12800 & 18432 & 36864 & 18432 & 135,764502 & $-0,987003$ & Tidạk:Signifikan \\
\hline 3000 & 75,5 & 27,577164 & 342,239682 & 760,5 & 117128 & 234256 & 117128 & 342,239682 & 0,220606 & TidajkSignifikan \\
\hline
\end{tabular}

\section{Koil Racing Bluthander dan Busi Standar}

Tabel 23.Hasil Uji T HC Koil Racing Bluthander dan Busi Standar

\begin{tabular}{|c|c|c|c|c|c|c|c|c|c|c|}
\hline RPM & $x-y$ & $\mathrm{Sx}$ & Sy & $s x^{2}$ & $\mathrm{sy}^{2}$ & $s x^{2}+s y^{2}$ & $s x^{2}+5 y^{2} / 2$ & $\sqrt{s x^{2}+s y^{2}}$ & $t$ & Sígnifikan \\
\hline 1500 & 549,5 & 153,442172 & 52,325902 & 23544,5 & 2738 & 5476 & 2738 & 52,325902 & 10,501491 & S:̧anifikan \\
\hline 2000 & 144 & 14,849242 & 191,625938 & 220,5 & 36720,5 & 73441 & 36720,5 & 191,625938 & 0,751464 & Túdak-Signifikan \\
\hline 2500 & 20,5 & 113,137085 & 67,175144 & 12800 & 4512,5 & 9025 & 4512,5 & 67,175144 & 0,305172 & TidakSignifikan \\
\hline 3000 & -15 & 27,577164 & 26,162951 & 760,5 & 684,5 & 1369 & 684,5 & 26,162951 & $-0,573330$ & T(șdakSignifikan \\
\hline
\end{tabular}




\section{Pembahasan}

Berdasarkan seluruh pembahasan menggunakan uji $t$ dapat dilihat bahwa perbedaan kadar emisi gas buang dari perpaduan beberapa jenis koil dan busi yang di uji pada putaran mesin 1500 dan putaran mesin 2000, putaran 2500 dan putaran mesin 3000 dari perpaduan beberapa jenis koil dan busi yang di uji, tapi dapat kita lihat bahwa penggunaan koil Standar di padukan dengan koil racing di dapat kan hasil terbaik pada penggunaan koil standar dan busi denso iridium, dan penggunaan koil racing kitaco dan busi yang dilakukan pengujian maka di dapatkan hasil perpaduan koil racing kitaco dan busi ngk iridium,sedangkan penggunaan koil racing bluthader dan busi di daptat kan hasil terbaik pada perpaduan koil kitaco dan busi denso iridium, dan perpaduan koil dan busi yang baik terdapat pada penggunaan koil racing bluethander dan busi ngk iridium yaitu kadar CO dan HC pada putaran mesin 1500 kadar CO nya 1,830 \%, dan HC 856 ppm, dan putaran mesin 2000 Kadar CO nya 1,655 \%, dan HC nya 284 ppm, dan putaran mesin 2500 kadar CO nya 0,715\% dan HC 472 ppm, sedangkan putaran 3000 kadar CO nya 0,810\%, dan HC 393,5 ppm. Oleh sebab itu koil racing Bluthander dan busi ngk iridium merupakan perpaduan yang baik untuk mengurangi kadar emisi gas buang karbonmonoksida dan hidrokarbon pada kendaraan bermotor, karna sangat pas untuk mengurangi kadar emisi gas buang CO dan HC pada Sepeda Motor Honda Supra X 125.

\section{SIMPULAN}

Terdapat perbedaan kadar emisi gas buang kendaraan bermotor dari semua jenis variasi koil dan busi yang di uji pada setiap putaran yang di lakukan. Terdapat perbedaan kadar emisi gas buang dari perpadaun koil dan busi, perpaduan koil Standar dan busi Standar menghasilkan kadar emisi gas buang karbonmonoksida dan hidaro karbon yang paling tinggi yaitu pada putaran 1500 kadar CO nya 2,075\% dan HC nya646,5 ppm, pada putaran2000 kadar CO nya 2,95\% dan HC nya 446,5 ppm, pada putaran 2500 kadar CO nya 4,215\% dan HC nya 528 ppm, pada putaran 3000 kadar CO nya 4,655\% dan HC nya 763,5 ppm. Sedangkan penggunaan koil racing bluthander dan busi ngk iridiumperpaduan koil racing dan busi paling baik yaitu kadar CO dan HC pada putaran mesin 1500 kadar CO nya 1,830 \%, dan HC 856 ppm, dan putaran mesin 2000 Kadar CO nya 1,655 \%, dan HC nya 284 ppm, dan putaran mesin 2500 kadar CO nya 0,715\% dan HC 472 ppm, sedangkan putaran 3000 kadar CO nya 0,810\%, dan HC 393,5 ppm.

\section{DAFTAR RUJUKAN}

\section{DAFTAR RUJUKAN}

[1] Jalius Jama, dkk. (2008). Teknik Sepeda Motor Jilid 1. Jakarta: Direktorat Pembinaan Sekolah Menengah Kejuruan.

[2] Toyota. (1972). Materi Pelajaran Engine Group Step 2. Jakarta: PT. Toyota Astra Motor.

[3] Wardan Suyanto. (1989). Teori Motor Bensin. Jakarta: Departemen Pendidikan dan Kebudayaan Direktorat Jendral Pendidikan Tinggi Proyek Pengembangan Lembaga Pendidikan Tenaga Kependidikan.

[4] Richard C. Flagan dan H. Seinfeld. (1988). Fundamentals of Air Pollution Engineering. Prentice-Hall, Inc: United States of America.

[5] Nugraha, Setya B. (2007). Aplikasi Teknologi Injeksi Bahan Bakar Elektronik (EFI) Untuk Mengurangi Emisi Gas Buang Sepeda Motor.Jurnal Ilmiah Populer dan Teknologi Terapan, Vol. 5. No.2. Hlm 692 - 706

[6] Subroto. (2009). Pengaruh Penggunaan Koil Racing Terhadap Unjuk Kerja Pada Motor Bensin.Skripsi tidak diterbitkan.Universitas Muhammadiyah Surakarta.

[7] Wahyu Hidayat. (2012). Motor Bensin Moderen. Jakarta: PT. Rineka Cipta 


\section{Biodata Penulis}

Oka Sandrio Putra aktif sebagai pengajar di jurusan Teknik Kendaraan Ringan SMKN 1 Gunung Talang. Menyelesaikan studi S1 Teknik Otomotif UNP.

M Nasir saat ini aktif mengajar dan juga bertanggung jawab sebagai kepala Laboratorium pengujian di Jurusan Teknik Otomotif Universitas Negeri Padang. 